Research Article

\title{
Experimental Study on the Strength and Deformation Characteristics of Concrete under True Triaxial Compression after Sulfate Attack
}

\author{
Wei Xia (D), ${ }^{1}$ Erlei Bai, ${ }^{1}$ Jinyu Xu, ${ }^{1,2}$ and Gaojie Liu ${ }^{1}$ \\ ${ }^{1}$ School of Aeronautical Engineering, Air Force Engineering University, Xi'an 710038, China \\ ${ }^{2}$ College of Mechanics and Civil Architecture, Northwest Polytechnic University, Xi'an 710072, China
}

Correspondence should be addressed to Wei Xia; xiaweiafeu@163.com

Received 9 February 2021; Revised 19 March 2021; Accepted 4 April 2021; Published 14 April 2021

Academic Editor: Yang Wu

Copyright (C) 2021 Wei Xia et al. This is an open access article distributed under the Creative Commons Attribution License, which permits unrestricted use, distribution, and reproduction in any medium, provided the original work is properly cited.

\begin{abstract}
To explore the mechanical properties of concrete under true triaxial static compressive load after sulfate attack, uniaxial static compression test and true triaxial static compression test at four stress ratios were carried out on concrete specimens immersed in $15 \%$ sulfate solution for 0-120 days by the integrated true triaxial static and dynamic load testing system, and the variation of performance indicators such as the strength and deformation of concrete under the coupling action of sulfate attack and complex stress state was analyzed. The results show that the uniaxial compressive strength of concrete increases at the beginning and then decreases with the increase of sulfate attack time and reaches the peak on the 30th day, with an increase rate of $16.57 \%$; the strength of concrete under triaxial compression increases significantly, and the maximum triaxial compressive strength is 3.18 times of uniaxial compressive strength under the combination of 0-day sulfate attack and 0.2:0.8 stress ratio; and the deterioration of concrete under sulfate attack is more prominent at high confining pressure, and as the sulfate attack worsens, the sensitivity of triaxial compressive strength of concrete to lateral compressive stress is reduced. In conclusion, triaxial compression can significantly enhance the ductility of concrete by playing a role in restraining the deformation and cracking of concrete after sulfate attack.
\end{abstract}

\section{Introduction}

Since the 21 st century, countries all over the world have paid increasing attention to the exploration and development of underground space resources. With the rapid development of advanced technology and further economic growth, the application breadth and depth of underground engineering structures are constantly expanding. Both civil infrastructure, such as urban subways and subsea tunnels, and military protective works, such as air raid shelters and underground oil depots, require massive underground building structures $[1,2]$, making concrete the most commonly used building material in today's engineering practice. The actual stress state of concrete materials differs greatly for buildings of different structure types and components in different parts of the building. For underground space structures, components and joints are generally under complex multiaxial stress state, resulting in discontinuous, heterogeneous, and anisotropic mechanical properties of the concrete [3-5]. Multiaxial test is a high-tech means to study the mechanical properties of concrete. Since the 1960s [6, 7], despite the limitation of test conditions and loading equipment, valuable data have been obtained from studies on multiaxial mechanical properties of concrete [8-14], and there are more conventional triaxial tests than true triaxial tests in existing studies. This is because two-dimensional principal stresses applied on the concrete in the conventional triaxial test are equal, while three-dimensional principal stresses in the true triaxial test are not, making it difficult to carry out a true triaxial test. However, the conventional triaxial test cannot represent the real stress state of the building structure, and only the true triaxial test 
under complex loading path can accurately simulate the actual working conditions.

Today, geotechnical engineering, water conservancy engineering, national defense engineering, and other underground development and utilization activities are in full swing. And, the durability of underground engineering structures should not be ignored $[15,16]$, as it is a decisive factor in determining the safety performance and service life of buildings. Among many factors threatening the durability of underground concrete structures in coastal areas and saline soil areas, salt attack is especially prominent. In particular, the sulfate attack of concrete involves physical, chemical, mechanical, and other processes and is very harmful [17-22], with complex influencing factors [23-27]. Sulfate attack can cause expansion and cracking of concrete, because of which the erosive medium can easily penetrate into the matrix and accelerate the deterioration process, leading to the loss of cohesion of cement hydration products and the decline of the overall resistance level of the concrete structure.

Considering the extremely complex service condition of underground concrete structures, it is particularly important and urgent to carry out in-depth studies on the mechanical properties of concrete materials under the coupling action of true triaxial stress state and sulfate attack. In view of this, we used the self-developed integrated true triaxial static and dynamic loading test system to carry out uniaxial quasistatic compression test and true triaxial static compression test on concrete specimens immersed in $15 \%$ sulfate solution for $0-120$ days. In these tests, the strength and deformation characteristics of concrete under sulfate attack and complex stress state was investigated, and the influencing mechanism of the coupling effect of sulfate attack and true triaxial static compression on the mechanical properties of concrete was analyzed and discussed, so as to provide references for the durability, design, and the prediction of resistance level of underground space concrete structures after sulfate attack. The findings in this study are of great significance for engineering applications and geophysical fields.

\section{Materials and Methods}

2.1. Raw Materials. Raw materials for preparing concrete specimens were cement, water, fine aggregates, coarse aggregates, and additives. Ordinary Portland cement grade 42.5 produced by Shaanxi Eco-Cement Co. Ltd. was used, and specific technical indexes are listed in Table 1. Tap water was used for mixing in the laboratory. Fine aggregates used were high-quality medium sand from Bahe River, and coarse aggregates were limestone gravels with a diameter of $5-10 \mathrm{~mm}$, which is hard and well graded. Key technical indexes of fine and coarse aggregates are shown in Tables 2 and 3. STHPC-03A FDN superplasticizer was used as the additive, with a water reducing rate of $23 \%$. The mix proportion was determined according to the Specification for Mix Proportion Design of Ordinary Concrete (JGJ 55-2011), as shown in Table 4. The sulfate solution for soaking concrete specimens was prepared using anhydrous sodium sulfate (AR grade, as shown in Figure 1) produced by Tianjin Zhiyuan Chemical Reagent Co. Ltd.

2.2. Specimen Preparation. Cubic concrete specimens with an edge length of $70.7 \mathrm{~mm}$ were used in the test. The preparation process comprised five steps: material preparation and dispensing, feeding and mixing, casting and curing, immersion and erosion, and grinding and smoothing. The specific process is as follows: (1) according to the determined mix proportion, accurately weigh the required raw materials; (2) pour sand, gravel, cement, and water into the mixer in turns, mix for $3 \mathrm{~min}$, and then manually mix the concrete mixture evenly; (3) put the concrete mix into the mold, move it to the vibration stand for compaction, and then move the mold indoor. After one day, remove the mold and carry out standard curing; (4) immerse the specimen after standard curing for 28 days in $15 \% \mathrm{Na}_{2} \mathrm{SO}_{4}$ solution for erosion, and replace the solution every 30 days, as shown in Figure 2; and (5) use SHM-200 double-end grinder to grind the specimen after the sulfate attack. Make sure that the surface roughness is less than $0.02 \mathrm{~mm}$.

2.3. Test Methods. We designed two tests on the mechanical properties of concrete after sulfate attack, as shown in Table 5. Both tests were carried out using the integrated true triaxial static and dynamic loading test system (as shown in Figure 3). The test system consisted of a static loading system (true triaxial tester) and a dynamic loading system (Hopkinson bar) $[28,29]$, which not only could test the static mechanical properties of concrete under multiaxial compression but also could carry out multiaxial compression dynamic test on the concrete at medium and high strain rates. The static loading system was composed of three parts: the computer control system, the electro-hydraulic servo control system, and the loading system. It could arbitrarily set the loading force and rate in all directions to meet the requirements of multiaxial complex path loading. The loading system had six independent loading subsystems (as shown in Figure 4). Each loading subsystem was composed of Jack, reaction frame, displacement sensor, and other components, and can realize three-dimensional $(x, y, z$-axis) independent loading on the uniaxial static compression test: after smearing the polished specimen surface evenly with butter, the specimen was placed between the loading plates of the true triaxial tester, and an anti-friction cushion was added between the loading surface and the loading plate. The loading mode was uniaxial (principal axis) quasi-static loading. The load was applied at a loading rate of $0.5 \mathrm{MPa} / \mathrm{s}$ until the concrete specimen was damaged.

True triaxial static compression test: the loading model is shown in Figure 5. Among the three loading directions, the load on $Z$-axis was vertical, while that on $X$-axis and $Y$-axis was horizontal, represented by principal stresses $\sigma_{1}, \sigma_{2}$, and $\sigma_{3}$, respectively. When determining the pre-applied load in true triaxial compression test, in order to avoid specimen failure before the load on the principal axis was applied, the compressive strength $f_{c, s}$ of the concrete specimen at each sulfate attack time measured in the uniaxial static 
TABLE 1: Main performance indexes of cement.

\begin{tabular}{|c|c|c|c|c|c|c|c|}
\hline \multirow[t]{2}{*}{ Fineness modulus } & \multirow[t]{2}{*}{ Density $\left(\mathrm{g} / \mathrm{cm}^{3}\right)$} & \multirow[t]{2}{*}{ Initial setting time (min) } & \multirow[t]{2}{*}{ Final setting time $(\min )$} & \multicolumn{2}{|c|}{$\begin{array}{l}\text { Compressive } \\
\text { strength } \\
(\mathrm{MPa})\end{array}$} & \multicolumn{2}{|c|}{$\begin{array}{c}\text { Flexural } \\
\text { strength } \\
(\mathrm{MPa})\end{array}$} \\
\hline & & & & $3 \mathrm{~d}$ & $28 \mathrm{~d}$ & $3 \mathrm{~d}$ & $28 \mathrm{~d}$ \\
\hline 1.6 & 3.16 & 110 & 245 & 33.2 & 52.7 & 6.4 & 9.1 \\
\hline
\end{tabular}

TABLE 2: Key technical indexes of sand.

\begin{tabular}{lcccc}
\hline Fineness modulus & Apparent density $\left(\mathrm{kg} / \mathrm{m}^{3}\right)$ & Bulk density $\left(\mathrm{kg} / \mathrm{m}^{3}\right)$ & Silt content $(\%)$ & Grade \\
\hline 2.7 & 2630 & 1500 & 1.3 & Qualified \\
\hline
\end{tabular}

TABLE 3: Key technical indexes of gravels.

\begin{tabular}{lccccc}
\hline Water content (\%) & Silt content (\%) & Content of flaky grains (\%) & Crushing value (\%) & Apparent density $\left(\mathrm{kg} / \mathrm{m}^{3}\right)$ & Bulk density $\left(\mathrm{kg} / \mathrm{m}^{3}\right)$ \\
\hline 0 & 0.4 & 8.7 & 8.6 & 2648 & 1598 \\
\hline
\end{tabular}

TABLE 4: Mix proportion of concrete.

\begin{tabular}{lcccccc}
\hline Water-cement ratio & Sand ratio (\%) & Cement $\left(\mathrm{kg} / \mathrm{m}^{3}\right)$ & Water $\left(\mathrm{kg} / \mathrm{m}^{3}\right)$ & Gravel $\left(\mathrm{kg} / \mathrm{m}^{3}\right)$ & Sand $\left(\mathrm{kg} / \mathrm{m}^{3}\right)$ & Water reducer $\left(\mathrm{kg} / \mathrm{m}^{3}\right)$ \\
\hline 0.3 & 40 & 495 & 150 & 1050 & 700 & 13.86 \\
\hline
\end{tabular}

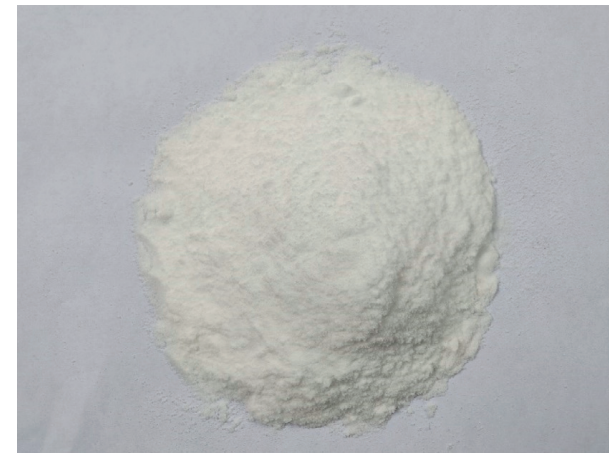

Figure 1: Anhydrous sodium sulfate.

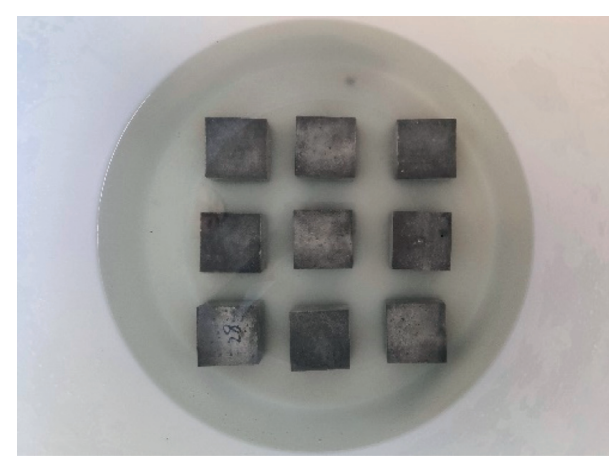

FIGURE 2: Concrete specimens immersed in sulfate solution.

compression test was taken as the reference value, and $20 \%$, $40 \%, 60 \%$, and $80 \% f_{c, s}$ were selected as load combinations. The stress ratio $\sigma_{1}: \sigma_{2}$ was set as $0.2: 0.2,0.2: 0.4,0.2: 0.6$, and $0.2: 0.8$. Loading process: (1) treat the surface of the

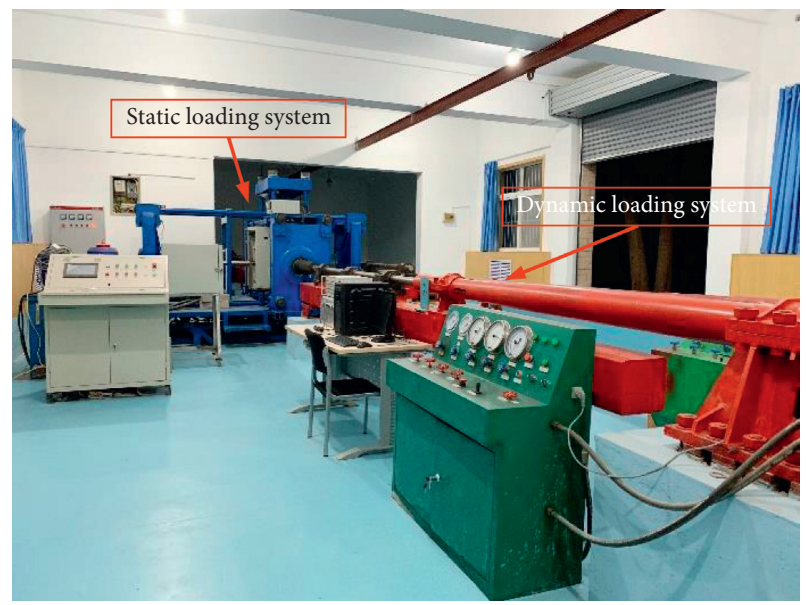

FIgURE 3: Integrated true triaxial static and dynamic loading test system.

specimen, then put the specimen on the testing machine, and take corresponding anti-friction measures; (2) start the testing machine, and adjust six loading heads on the $X, Y$, and $Z$ axes with the control system until they are aligned with the center of the end face of the specimen at a distance of 1-2 mm; (3) preload: input the load value corresponding to the predetermined stress ratio, and carry out lateral pressure loading in the $X$-axis and $Z$-axis direction by the static loading system; (4) load: after lateral pressure loading, apply load in the principal axis ( $Y$-axis) direction until the specimen is damaged, during which the computer automatically collects and records the test data. To ensure the accuracy and reliability of test results, at least 3 specimens were tested under each sulfate attack time and stress state. 
TABLE 5: Loading scheme of the test.

\begin{tabular}{lccc}
\hline Test type & $X$-axis & $Y$-axis (principal axis) & $Z$-axis \\
\hline Uniaxial quasi-static compression & - & Static load & - \\
True triaxial static compression & Static load & Static load & Static load \\
\hline
\end{tabular}

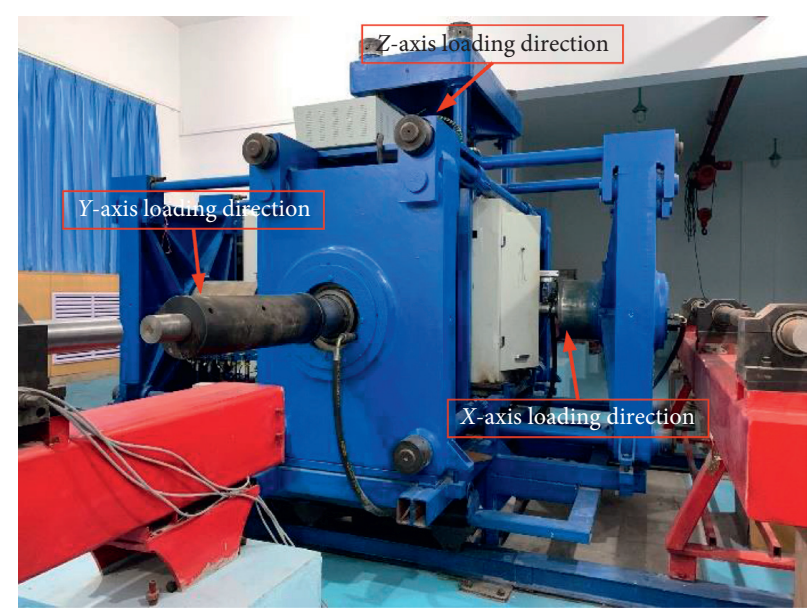

FIGURE 4: Static loading system.
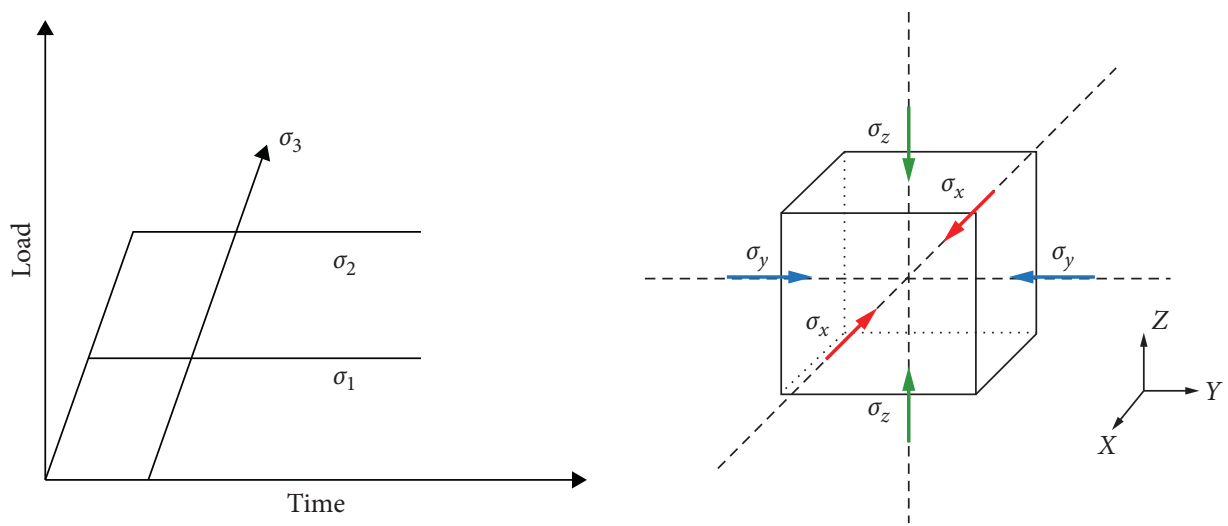

Figure 5: Loading model of true triaxial static compression test.

\section{Basic Damage Characteristics of Concrete after Sulfate Attack}

3.1. Surface Appearance Changes. As shown in Figure 6, as the immersion time of specimens in sulfate solution extends, the surface morphology of concrete gradually changes due to salt attack. At the initial stage of erosion (0-30 days), a salting-out phenomenon was observed, as a small number of white crystals were found in pores on the specimen surface. In the later stage of erosion (60-120 days), the specimen surface became white, the number of crystals in pores increased, obvious dusting was observed, and the edges and corners of some specimens even fall off. This may be because in the process of sulfate attack, the side faces of the specimen were one-way attacked by sulfate ions, while the edges and top corners of the specimen were two-way and three-way attacked by sulfate ions. Assuming that the attack rate of sulfate ions is the same, the concentration of sulfate ions at the corners of the specimen is higher than that at the side faces, for which cause the erosion speed and degree by sulfate ions are more obvious at edges. Macroscopically, after the concrete specimens were immersed in sulfate solution, the edges and corners first fall off, and then the erosion slowly propagates to the side faces of the specimen. In addition, micro cracks were found on the surface of some specimens, which are mainly attributed to the volume expansion of erosion products. Sulfate crystallization also accelerated the generation and growth of microcracks [30].

3.2. Mass Change. Test procedure for the mass change of concrete specimens: take out the specimen soaked in the solution for a certain time and clean its surface, and then dry it in the oven at $60^{\circ} \mathrm{C}$ (ettringite decomposes at about $70^{\circ} \mathrm{C}$ ). Weigh the specimen after it cools down to room temperature. The mass data of specimens immersed in sulfate 

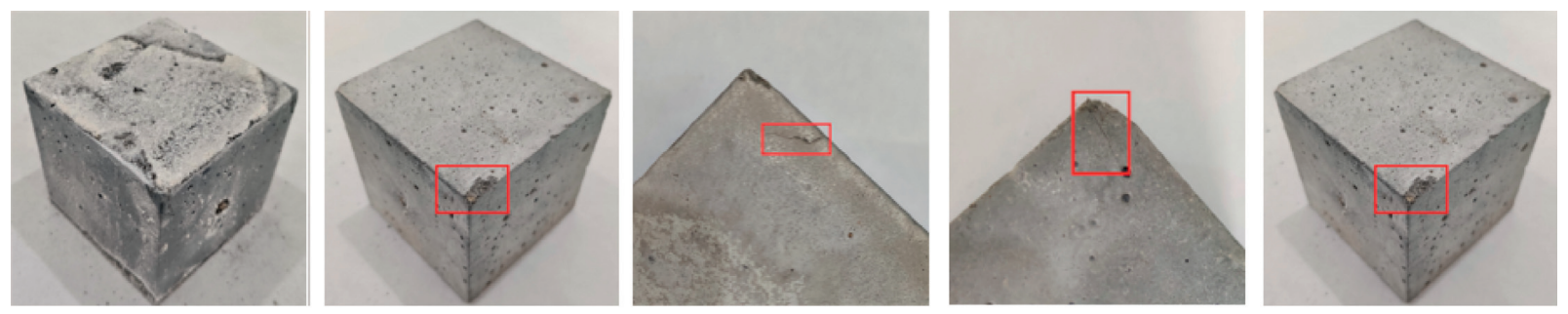

FIGURE 6: Surface crystallization, corners falling off, spalling, and cracking of concrete specimens.

solution for different days are shown in Table 6. The mass change rate of each group of specimens is calculated using formula (1). Figure 7 shows the mass change curve of specimens with time.

$$
R=\frac{M_{t}-M_{0}}{M_{0}} \times 100 \%
$$

where $M_{t}$ is the mass of the specimen after $t$ days of sulfate attack (g); $M_{0}$ is the mass of the specimen without sulfate attack (g); and $R$ is the mass change rate (\%) of the specimen after $t$ days of sulfate attack.

From Table 6 and Figure 7, the mass change of concrete specimens after immersion in sulfate solution shows an upward trend as the attack time increases. The mass increases by $1.32 \%$ after 120 days of immersion, and is most notable in the early stage of erosion. The mass change rate reached $0.70 \%$ after 30 days of immersion, which accounted for $52.84 \%$ of the total mass change rate. There are two causes for the mass change: one is that the concrete specimen soaked in the solution continuously absorbs water and hydrates causing the mass increase; the other is that insoluble minerals were generated inside the specimen due to sulfate attack, causing the weight gain. Ettringite, gypsum, and other expansive substances generated by the chemical reaction of sulfate ions and concrete filled the internal pores of the specimen, which continuously densify the specimen and hinder the penetration and diffusion of the solution. However, with the increase of erosion products, the volume of the specimen continues to expand, the internal stress continues to accumulate, and micro cracks and other damages begin to appear in the concrete, which further promotes sulfate attack. Therefore, in the macroscopic view, the mass change of concrete specimens is characterized by a sharp increase at the beginning, unchanged in the middle stage, and slow increase in the later stage.

3.3. Uniaxial Static Compressive Strength. This section mainly studies the variation of the strength of concrete specimens immersed in sulfate solution at different sulfate attack times and the comparison of concrete strength between concrete specimens immersed in sulfate solution and clean water at the same age. The corrosion resistance coefficient is calculated using

$$
K=\frac{f_{c, s}}{f_{c, w}}
$$

TABLE 6: Mass of concrete specimens at different attack times.

\begin{tabular}{lc}
\hline Attack time $(\mathrm{d})$ & Mass $(\mathrm{g})$ \\
\hline 0 & 851.12 \\
15 & 856.93 \\
30 & 857.55 \\
45 & 858.67 \\
60 & 859.91 \\
75 & 860.67 \\
90 & 861.50 \\
105 & 861.86 \\
120 & 862.22 \\
\hline
\end{tabular}

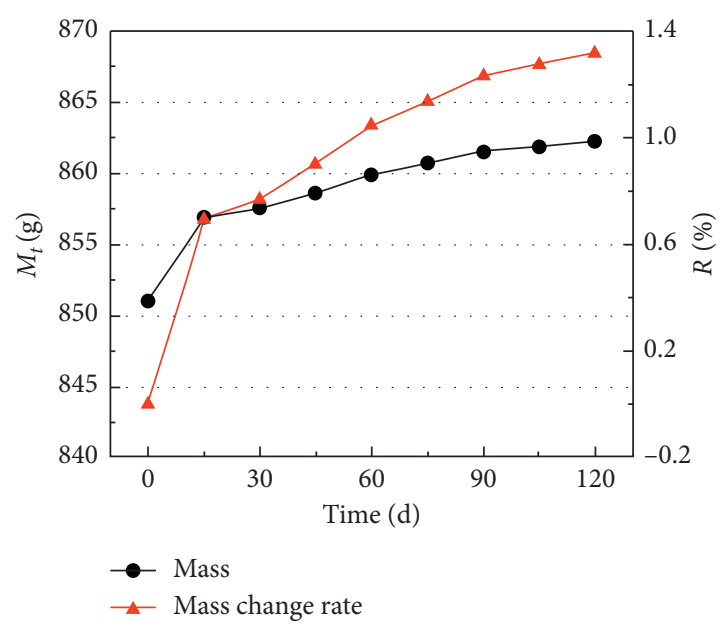

FIgURE 7: Mass change curve of concrete specimens with attack time.

, where $K$-the corrosion resistance coefficient of uniaxial compressive strength, $K>1$ means that the concrete is reinforced, and $K<1$ means that the concrete is deteriorated; $f_{c, s}-$ compressive strength of concrete after sulfate attack at different ages; $f_{c, w}$-compressive strength of concrete soaked in water at different ages.

The compressive strength and corrosion resistance coefficient of specimens in each group are listed in Table 7, and the variation of compressive strength and corrosion resistance coefficient with time are shown in Figures 8 and 9, where Group W refers to specimens immersed in clean water and Group S refers to specimens immersed in sulfate solution. As can be observed from Figure 8, with the increase of immersion time, the compressive strength of specimens immersed in clean water continues to increase, with a total 
TABLE 7: Uniaxial compressive strength and corrosion resistance coefficient of concrete specimens.

\begin{tabular}{|c|c|c|c|c|c|c|c|c|c|}
\hline \multirow{2}{*}{ Time $(\mathrm{d})$} & \multicolumn{3}{|c|}{ Group W } & \multicolumn{3}{|c|}{ Group S } & \multirow{2}{*}{ Average strength of group $\mathrm{W}(\mathrm{MPa})$} & \multirow{2}{*}{ Average strength of group S $(\mathrm{MPa})$} & \multirow{2}{*}{$K$} \\
\hline & 1 & 2 & 3 & 1 & 2 & 3 & & & \\
\hline 0 & 55.14 & 58.15 & 56.15 & 55.14 & 58.15 & 56.15 & 56.48 & 56.48 & 1.00 \\
\hline 30 & 60.14 & 63.54 & 62.41 & 62.12 & 64.42 & 63.27 & 62.03 & 63.27 & 1.02 \\
\hline 60 & 61.04 & 65.68 & 63.96 & 59.71 & 64.13 & 63.03 & 63.56 & 62.29 & 0.98 \\
\hline 90 & 65.36 & 66.24 & 62.58 & 62.31 & 58.34 & 60.04 & 64.76 & 60.23 & 0.93 \\
\hline 120 & 67.79 & 66.62 & 63.11 & 52.86 & 58.09 & 56.93 & 65.84 & 55.96 & 0.85 \\
\hline
\end{tabular}

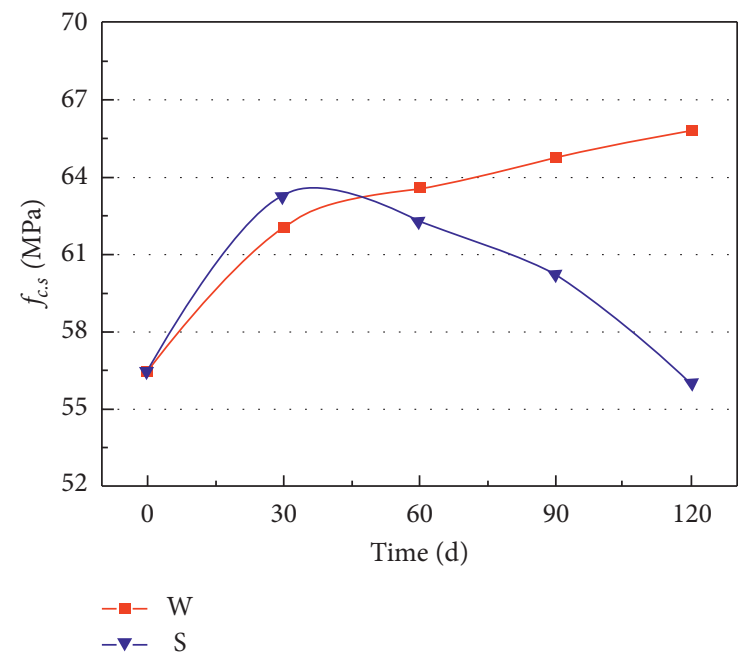

Figure 8: Variation of compressive strength of concrete specimens over time.

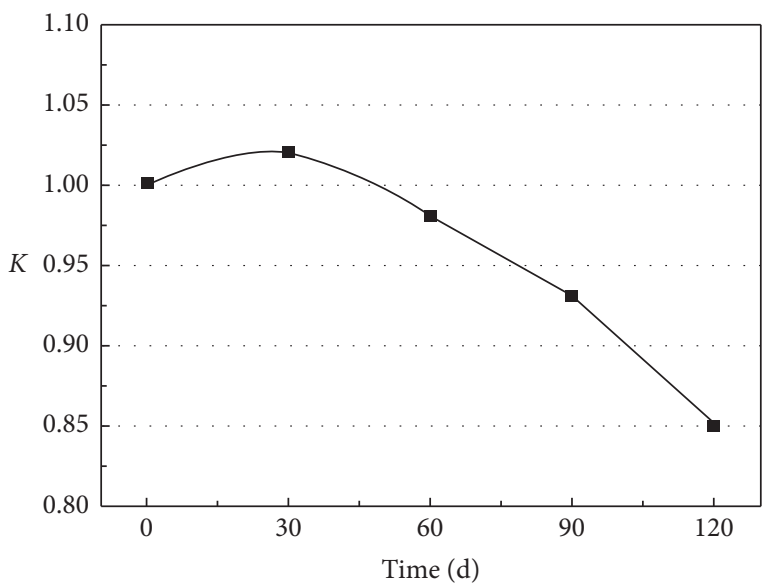

FIGURE 9: Variation of corrosion resistance coefficient of concrete specimens over time.

increase of $16.57 \%$, while that of specimens in Group S first increases and then decreases, with the maximum increase rate of $12.02 \%$ observed on the 30 th day of erosion. The compressive strength of specimens in Group $\mathrm{S}$ is greater than that in Group W on the 30th day of erosion, which indicates that at the initial stage, concrete specimens immersed in sulfate solution are more reinforced than those immersed in water. As the erosion time increases, the compressive strength of Group S continues to decrease, and on the 120th day, the compressive strength of Group S was only $85 \%$ of that of Group W. It can be seen from Figure 8 that the corrosion resistance coefficient of the specimen first slightly increases to 1.02 and then continuously decreases to 0.85. On the 30th day, the strength of specimens in Group S is only increased by $2 \%$ compared with that in Group W, but is $12.02 \%$ higher than those not immersed in sulfate solution. This indicates that the increase of concrete strength in the early stage of erosion is mainly caused by the continuous hydration of concrete. After 30 days of erosion, the decline of corrosion resistance coefficient slightly accelerates, indicating that the internal damage of concrete will promote the strength deterioration.

3.4. Discussion. The variation of compressive strength of concrete specimens after immersion in sulfate solution can be attributed to two factors: (1) continuous hydration caused by immersion. In the process of erosion, when the specimens are immersed in sulfate solution, the unfinished hydration continues in the concrete, causing the strength of concrete to increase continuously. This strength increase is characterized by a large increase in the early stage and a small increase in the later stage. (2) Erosion by sulfate medium. The invasion of $\mathrm{Na}_{2} \mathrm{SO}_{4}$ in the solution into the specimen follows three basic principles: the first one is the penetration of the solution into the specimen due to the pressure gradient difference transferring from high pressure to low pressure; the second one is the diffusion of the solution into the specimen due to the concentration difference transferring from high concentration to low concentration; and the third one is the invasion of the solution into the specimen due to the capillary suction generated by the capillary action of the internal pore system in the concrete. When fully immersed in the sulfate solution, concrete specimens are subject to the chemical erosion and destruction caused by sulfate. Chemical erosion is actually a reaction between sulfate ions and cement hydration products, which forms expansive salts. There are four types of failure caused by sulfate attack by failure form and erosion product, as they are as follows: ettringite-induced failure, gypsum-induced failure, $\mathrm{Na}_{2} \mathrm{SO}_{4}$ dissolution-induced failure, and carborundum-induced failure. In this experiment, as the erosion medium is sodium sulfate, the resulting erosion failures are mainly ettringiteinduced failure and gypsum-induced failure.

3.4.1. Ettringite-Induced Failure. Ettringite in concrete, namely, calcium sulfoaluminate hydrate $\left(3 \mathrm{CaO} \cdot \mathrm{Al}_{2} \mathrm{O}_{3}\right.$. $\left.3 \mathrm{CaSO}_{4} \cdot 32 \mathrm{H}_{2} \mathrm{O}\right)$, is mainly formed by the topological 
chemical reaction of sulfate in solution with $\mathrm{Ca}(\mathrm{OH})_{2}$ and calcium aluminate hydrate $\left(\mathrm{C}_{3} \mathrm{AH}_{6}\right)$. The chemical reactions involved are as follows:

$$
\begin{gathered}
\mathrm{CaO} \cdot \mathrm{H}_{2} \mathrm{O}+\mathrm{Na}_{2} \mathrm{SO}_{4}+2 \mathrm{H}_{2} \mathrm{O} \longrightarrow \mathrm{CaSO}_{4} \cdot 2 \mathrm{H}_{2} \mathrm{O}+2 \mathrm{NaOH} \\
3 \mathrm{CaO} \cdot \mathrm{Al}_{2} \mathrm{O}_{3}+3\left(\mathrm{CaSO}_{4} \cdot 2 \mathrm{H}_{2} \mathrm{O}\right)+26 \mathrm{H}_{2} \mathrm{O} \longrightarrow 3 \mathrm{CaO} \cdot \mathrm{Al}_{2} \mathrm{O}_{3} \cdot 3 \mathrm{CaSO}_{4} \cdot 32 \mathrm{H}_{2} \mathrm{O} \\
\mathrm{CaO} \cdot \mathrm{Al}_{2} \mathrm{O}_{3}+3\left(\mathrm{CaSO}_{4} \cdot 2 \mathrm{H}_{2} \mathrm{O}\right)+2 \mathrm{Ca}(\mathrm{OH})_{2}+24 \mathrm{H}_{2} \mathrm{O} \longrightarrow 3 \mathrm{CaO} \cdot \mathrm{Al}_{2} \mathrm{O}_{3} \cdot 3 \mathrm{CaSO}_{4} \cdot 32 \mathrm{H}_{2} \mathrm{O} \\
3\left(\mathrm{CaO} \cdot \mathrm{Al}_{2} \mathrm{O}_{3}\right) \cdot \mathrm{CaSO}_{4}+8 \mathrm{CaSO}_{4}+6 \mathrm{CaO}+96 \mathrm{H}_{2} \mathrm{O} \longrightarrow 3\left(3 \mathrm{CaO} \cdot \mathrm{Al}_{2} \mathrm{O}_{3} \cdot 3 \mathrm{CaSO}_{4} \cdot 32 \mathrm{H}_{2} \mathrm{O}\right)
\end{gathered}
$$

Ettringite is an insoluble expansive erosion product. The maximum volume expansion of ettringite can reach as high as 2.5 times and the absolute volume of solid phase can be increased by 1.5 times. Due to the continuous invasion of sulfate ions, the erosion products will be generated and accumulated in the specimen. As corrosion products expand, the pore wall of the material is squeezed to produce expansion stress, and cracks start to form and grow from the inside to the outside. The bond between the hardened cement paste and the aggregates is destroyed due to the expansion stress, and macroscopically more cracks are generated, leading to the decrease of compressive strength of the specimen.

3.4.2. Gypsum-Induced Failure. Studies have found that when the solubility product of $\mathrm{SO}_{4}^{2-}$ and $\mathrm{Ca}^{2+}$ in the solution exceeds that of gypsum, gypsum will crystallize. Therefore, the concentration of $\mathrm{SO}_{4}^{2-}$ in the erosion solution plays an important role in gypsum formation. In this experiment, the concentration of sodium sulfate solution is $15 \%$, which is close to the saturated solution at room temperature. Hence, $\mathrm{Ca}(\mathrm{OH})_{2}$ in the specimen is easy to react with $\mathrm{SO}_{4}^{2-}$ and form gypsum, which then crystallizes. The destructive effect of gypsum precipitation on concrete is mainly reflected in two aspects: on the one hand, when $\mathrm{Ca}(\mathrm{OH})_{2}$ is transformed into gypsum, its volume will be doubled, resulting in expansive failure in the specimen; on the other hand, as gypsum is the reaction product of $\mathrm{Ca}(\mathrm{OH})_{2}$ and $\mathrm{SO}_{4}^{2-}$, the continuous consumption of $\mathrm{Ca}(\mathrm{OH})_{2}$ in the reaction lead to the softening of concrete and macroscopic decrease of compressive strength of the specimen.

As shown in Figure 10, as the erosion time extends, the products of sulfate attack continue to form and accumulate in the specimen. At the same time, with the continuous consumption of water by the chemical reaction, sodium sulfate in the solution crystallizes. The sulfate attack on concrete is a long-term and slow process. According to the variation of compressive strength, the sulfate attack process can be divided into two stages, namely, the concrete strength increasing stage (before 30 days) and the concrete strength decreasing stage (after 30 days). The specific mechanism is that, at the initial stage, the products of sulfate attack expand and fill part of the pores in the specimen. Macroscopically, the compactness and compressive strength of the specimen are increased. With the increase of erosion time, the erosion products gradually increase and deposit in the pores, and the internal stress caused by its expansion also accumulates. After reaching a certain extent, it begins to destroy the internal structure of the concrete, and produces more new cracks and other damage, resulting in the decrease of the compressive strength of the specimen. These new cracks will promote the diffusion of sulfate ions, which in turn accelerates the sulfate attack, showing a positive feedback effect.

In conclusion, the variation of uniaxial compressive strength of concrete under sulfate attack is a complex process, which is closely related to its internal micro composition and microstructure. Most literatures show that the inflection point of compressive strength decline in the test is around 60-120 days, while in this study, the inflection point occurs between 3 and 60 days. This may be because cubic concrete specimens with an edge length of $70.7 \mathrm{~mm}$ is used, and the mass fraction of sulfate solution is $15 \%$, while other researchers usually use cubic specimens with an edge length of $100 \mathrm{~mm}$ or $150 \mathrm{~mm}$, and the concentration of corrosion solution is less than $10 \%$. The process of sulfate attack on the concrete is accelerated due to the smaller specimen size and $15 \%$ sulfate solution.

\section{Mechanical Properties of Concrete under True Triaxial Compression}

4.1. Test Results. Table 8 shows the true triaxial static compression test results of concrete specimens under different sulfate attack times and lateral compressive stress ratios.

4.2. Triaxial Compressive Strength. Figure 11 shows the variation of true triaxial compressive strength of concrete specimens. From the figure: (1) the compressive strength of concrete under triaxial compression is significantly higher than that of concrete under uniaxial compression, and the second principal stress $\sigma_{2}$ is a critical factor affecting the triaxial compressive strength. When the third principal stress $\sigma_{1}$ remains constant, the triaxial compressive strength of concrete increases with the increase of the second principal stress $\sigma_{2}$, with an obvious confining 

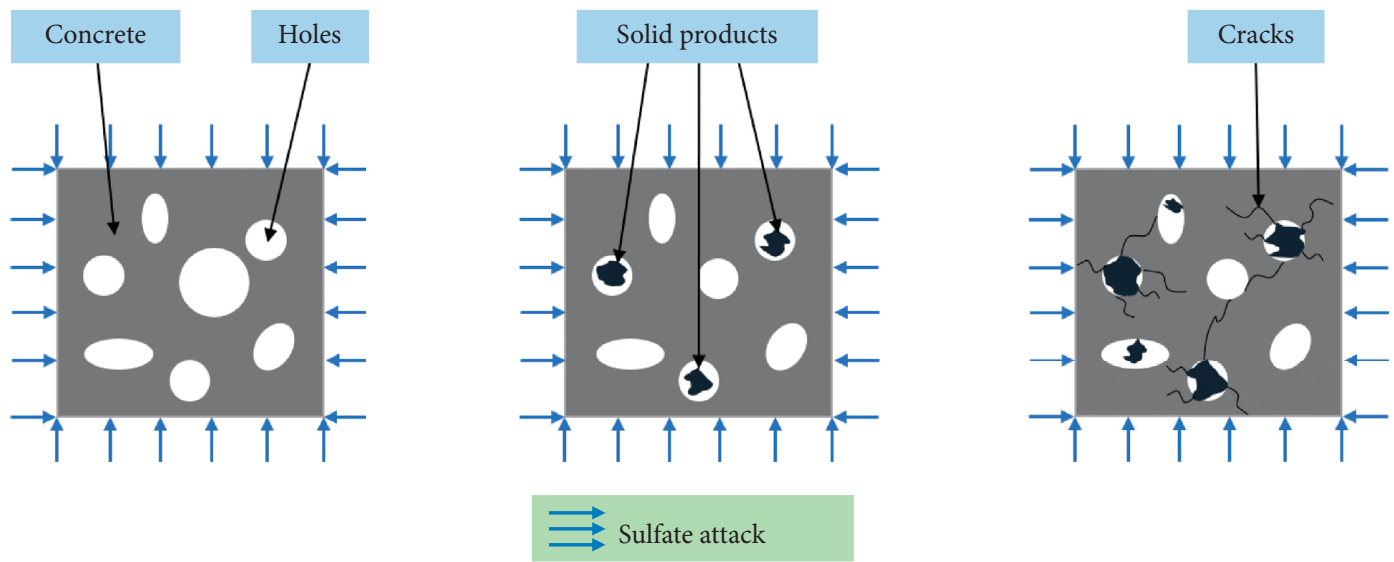

Figure 10: Process of sulfate attack on concrete.

TABLE 8: True triaxial static compression test results of concrete after sulfate attack.

\begin{tabular}{|c|c|c|c|c|c|}
\hline Test no. & Attack time (d) & $\sigma_{1}: \sigma_{2}$ & $\sigma_{3}(\mathrm{MPa})$ & $\sigma_{3} / f_{c, s}$ & $\varepsilon\left(\times 10^{-3}\right)$ \\
\hline \multirow{5}{*}{ TA-S-0 } & \multirow{5}{*}{0} & Uniaxial & 56.48 & 1 & - \\
\hline & & $0.2: 0.2$ & 88.67 & 1.57 & 17.28 \\
\hline & & $0.2: 0.4$ & 142.23 & 2.52 & 23.85 \\
\hline & & $0.2: 0.6$ & 165.99 & 2.94 & 24.19 \\
\hline & & $0.2: 0.8$ & 179.56 & 3.18 & 25.57 \\
\hline \multirow{5}{*}{ TA-S-30 } & \multirow{5}{*}{30} & Uniaxial & 63.27 & 1 & - \\
\hline & & $0.2: 0.2$ & 109.47 & 1.73 & 16.13 \\
\hline & & $0.2: 0.4$ & 149.49 & 2.36 & 21.48 \\
\hline & & $0.2: 0.6$ & 179.95 & 2.84 & 24.81 \\
\hline & & $0.2: 0.8$ & 181.77 & 2.87 & 24.12 \\
\hline \multirow{5}{*}{ TA-S-60 } & \multirow{5}{*}{60} & Uniaxial & 62.29 & 1 & - \\
\hline & & $0.2: 0.2$ & 95.45 & 1.53 & 14.32 \\
\hline & & $0.2: 0.4$ & 135.47 & 2.17 & 22.82 \\
\hline & & $0.2: 0.6$ & 162.09 & 2.60 & 26.36 \\
\hline & & $0.2: 0.8$ & 162.87 & 2.61 & 24.68 \\
\hline \multirow{5}{*}{ TA-S-90 } & \multirow{5}{*}{90} & Uniaxial & 60.23 & 1 & - \\
\hline & & $0.2: 0.2$ & 97.85 & 1.62 & 13.59 \\
\hline & & $0.2: 0.4$ & 122.07 & 2.03 & 24.97 \\
\hline & & $0.2: 0.6$ & 138.00 & 2.29 & 27.73 \\
\hline & & $0.2: 0.8$ & 152.05 & 2.52 & 27.52 \\
\hline \multirow{5}{*}{ TA-S-120 } & \multirow{5}{*}{120} & Uniaxial & 55.96 & 1 & - \\
\hline & & $0.2: 0.2$ & 74.36 & 1.33 & 12.62 \\
\hline & & $0.2: 0.4$ & 123.18 & 2.20 & 18.12 \\
\hline & & $0.2: 0.6$ & 135.79 & 2.43 & 19.84 \\
\hline & & $0.2: 0.8$ & 133.63 & 2.39 & 19.90 \\
\hline
\end{tabular}

pressure reinforcement effect; (2) under the same sulfate attack time, the triaxial compressive strength increases linearly with the increase of stress ratio from $0.2: 0.2$ to 0.2 : 0.6 , and the strength increase slows down or even slightly decreases when the stress ratio increases from $0.2: 0.6$ to 0.2:0.8 (after 120 days of attack); (3) at the same stress ratio, the triaxial compressive strength of the specimen increases slightly in the early stage of erosion (0-30 days). With the increase of erosion time, the degree of erosion deepens, and the compressive strength continues to decline after 30 days. On the whole, the lower the confining pressure level is, the smaller the impact of sulfate attack on concrete is, and the smaller the compressive strength decline is. However, at high stress levels (0.2: 0.6 and 0.2: 0.8 ), obvious decrease of triaxial compressive strength is observed, which indicates that with the increase of the confining pressure, the deterioration effect of sulfate attack becomes increasingly significant.

To rule out the influence of erosion time on the erosion of concrete specimens, the influence of confining pressure on the compressive strength of concrete is further studied. $\sigma_{3} / f_{c, s}$ is calculated, and the variation curve of erosion time and stress ratio is plotted, as shown in Figure 12. As can be observed from the figure: (1) after the uniaxial compression is changed to lateral compressive stress ratio of $0.2: 0.2$, the $\sigma_{3} / f_{c, s}$ is between 1.33 and 1.73 at different erosion times, and 

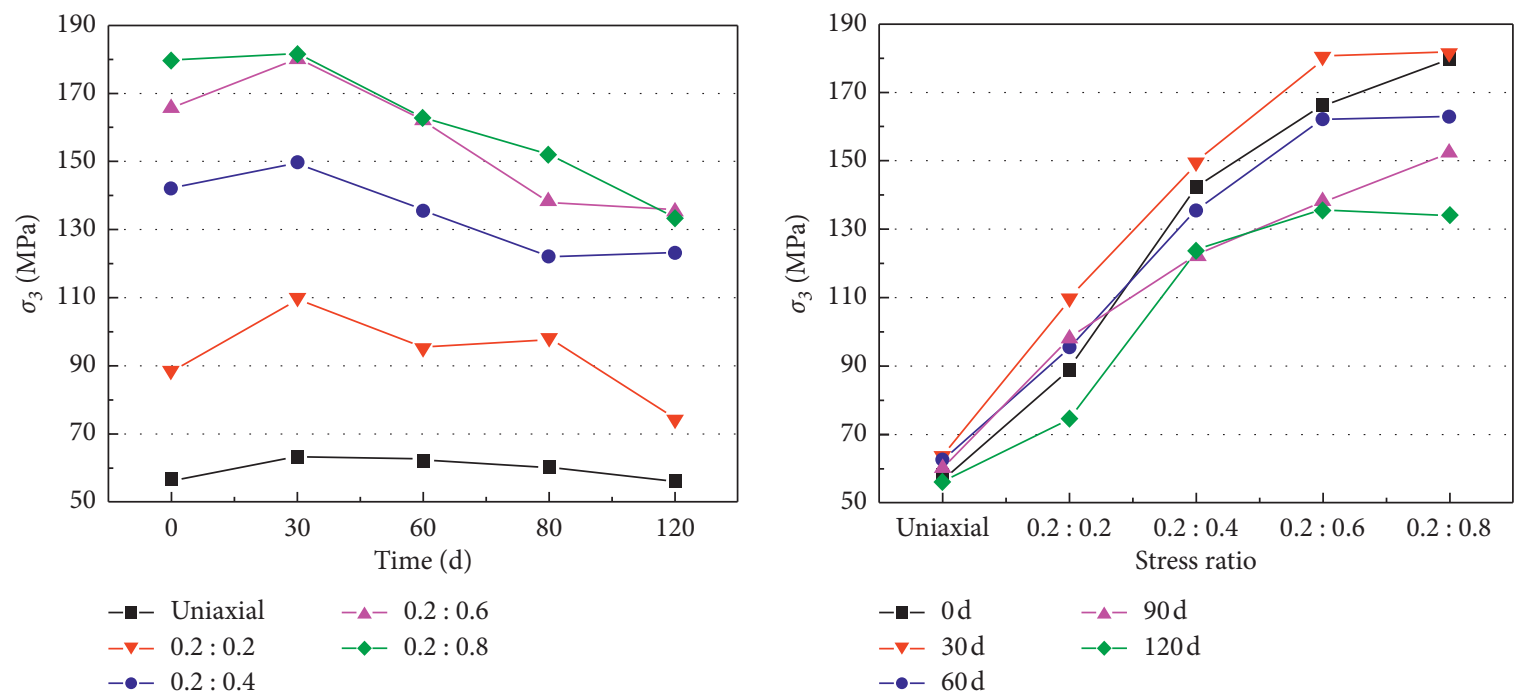

FIGURE 11: Variation of true triaxial compressive strength of concrete specimens.

the compressive strength of the specimen is significantly improved, and continues to improve with the increase of lateral compressive stress level (a slight decrease is observed in specimens in the 120-day group); (2) at the same stress ratio, the $\sigma_{3} / f_{c, s}$ decreases continuously with the increase of erosion time. On the 120th day, $\sigma_{3} / f_{c, s}$ of specimens in 0.2 : 0.4 and $0.2: 0.6$ groups increases slightly, but on the whole shows a downward trend, and is kept above 1.33 ; (3) under the combination of $0.2: 0.8$ stress ratio and 0 -day immersion, the compressive strength of the specimen increases most significantly, and the $\sigma_{3} / f_{c, s}$ reaches 3.18 , while under the combination of $0.2: 0.2$ stress ratio and 120-day immersion, the compressive strength of the specimen increases by only $33 \%$.

The notable difference of the stress state of concrete under different stress ratio combinations also affects the test results to a certain extent. To comprehensively consider the influence of the third principal stress $\sigma_{1}$ and the second principal stress $\sigma_{2}$ on the first principal stress $\sigma_{3}$, the lateral compressive stress level $\bar{\sigma}$ is defined to characterize the vector sum of $\sigma_{1}$ and $\sigma_{2}$, as follows:

$$
\bar{\sigma}=\sqrt{\sigma_{1}^{2}+\sigma_{2}^{2}}
$$

The relationship between the lateral compressive stress level $\bar{\sigma}$ and the triaxial compressive strength $\sigma_{3}$ is shown in Figure 13. The horizontal ordinate is $\bar{\sigma} / f_{c, s}$ and the vertical ordinate is $\sigma_{3} / f_{c, s}$. It can be seen that there is a good linear relationship between them. The regression analysis results are expressed in equation (8). It can be seen that under triaxial compression, if the crushing damage caused by high hydrostatic pressure is ignored, the triaxial compressive strength of concrete specimens increases monotonously with the increase of lateral compressive stress $\bar{\sigma}$. In addition, with the increase of soaking time of specimens in sulfate solution, the slope of the fitting curve shows a downward trend, which indicates that the sensitivity of triaxial compressive strength to lateral compressive stress decreases as the erosion degree deepens.

$$
\begin{cases}\frac{\sigma_{3}}{f_{c, s}}=\frac{0.9858+2.8637 \bar{\sigma}}{f_{c, s}}, & R^{2}=0.8882, \\ \frac{\sigma_{3}}{f_{c, s}}=\frac{1.2867+2.1321 \bar{\sigma}}{f_{c, s}}, & R^{2}=0.8516, \\ \frac{\sigma_{3}}{f_{c, s}}=\frac{1.1369+2.0012 \bar{\sigma}}{f_{c, s}}, & R^{2}=0.8398, \\ \frac{\sigma_{3}}{f_{c, s}}=\frac{1.2270+1.6273 \bar{\sigma}}{f_{c, s}}, & R^{2}=0.9586, \\ \frac{\sigma_{3}}{f_{c, s}}=\frac{1.0819+1.8367 \bar{\sigma}}{f_{c, s}}, & R^{2}=0.8063 .\end{cases}
$$

4.3. Peak Strain and Failure Pattern. In view of the complex deformation behavior and failure pattern of concrete under multiaxial stress, the peak strain corresponding to the peak stress in triaxial static compression test is used to characterize the deformation behavior of the specimen under triaxial load, and the typical failure pattern under this loading mode is analyzed.

Figure 14 shows the peak strain variation of specimens under different attack times and stress ratio. As can be observed from the figure: (1) under the same sulfate attack time, as the stress ratio increases, there are two changing trends of peak strain of the specimen. One is that before sulfate attack (0-day), when the stress ratio is increased from $0.2: 0.2$ to $0.2: 0.4$, the peak strain increases significantly, with an increase of $38 \%$; when increased to $0.2: 0.6$, the peak strain approximately remains unchanged; and when increased to $0.2: 0.8$, the peak strain slightly increases again; and the other trend is that after sulfate attack (30-120 days), as the stress ratio increases, the peak strain shows sharp increase at the stress ratio of $0.2: 0.4$, and increases by $33 \%$, 

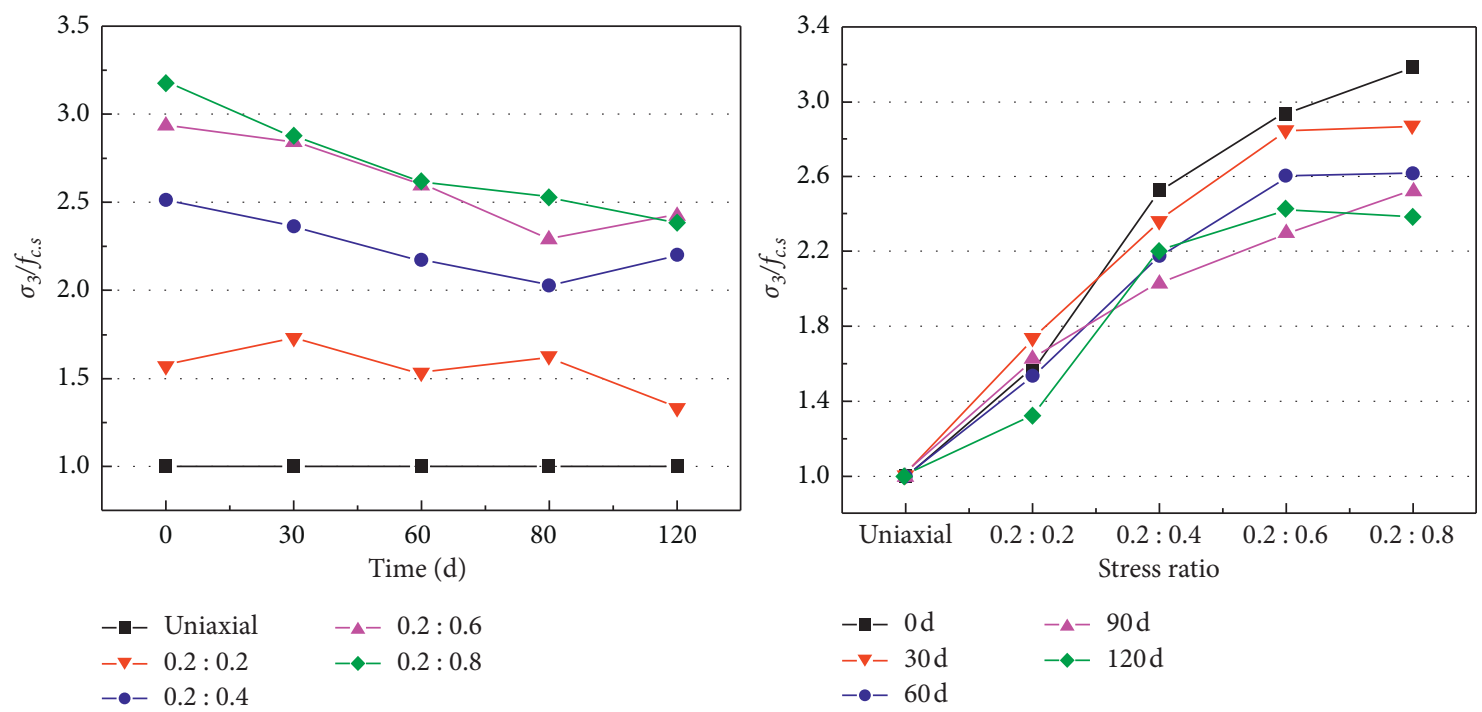

Figure 12: Variation of $\sigma_{3} / f_{c, s}$ under different erosion time and stress ratios.

$59 \%, 84 \%$, and $44 \%$, respectively. When the stress ratio is $0.2: 0.6$, the increase rate slows down, and at $0.2: 0.8$, the peak strain remains unchanged or even slightly declines; (2) under different stress ratios, the relationship between attack time and peak strain does not show a regular change. After 0-90 days of attack, the peak strain fluctuates in a small range at four stress ratios. The peak strain of specimens in high stress ratio groups $(0.2: 0.6$ and $0.2: 0.8)$ increases slightly, while that of specimens in the $0.2: 0.4$ stress ratio group remains the same, and that of specimens in the low stress ratio group $(0.2: 0.2)$ increases slightly, showing a downward trend. On the 120th day of sulfate attack, the peak strain of specimens in the $0.2: 0.4-0.8$ stress ratio groups decreases sharply; and (3) on the whole, under the same stress ratio, the peak strain of specimens in the 120-day erosion group is the smallest, while under the same erosion time, the peak strain of the low stress ratio group $(0.2: 0.2)$ is the smallest, and the specimens exhibit the worst deformation performance.

In the true triaxial compression test, there are five typical failure patterns of cubic concrete specimens, as follows: oblique shear failure, flaky splitting, squeeze flow, tensile fracture, and columnar crushing [14, 31-33]. In the triaxial static compression test of concrete, as erosion time is not a critical factor affecting the failure pattern, the influence of stress ratio on concrete is mainly analyzed [34, 35]. The typical failure pattern and crack characteristics of the specimen are shown in Figure 15. Figure 16 shows the broken state of the specimen after dismantling under different stress ratios after 120 days of erosion. It can be seen from Figure 15 that the failure pattern of the specimen is between splitting failure and oblique shear failure. The maximum stress ratio combinations used in this test are $\sigma_{1} /$ $f_{c, s}=0.2$ and $\sigma_{2} / f_{c, s}=0.8$. When $\sigma_{1} / \sigma_{3} \leq 0.15$ and $\sigma_{2} / \sigma_{3}>0.15$, the intermediate principal stress exceeds a certain threshold; the columnar splitting failure, that is, the splitting failure along the direction perpendicular to the principal stress, is less likely to occur. As a result, the concrete specimen exhibits splitting failure along the plane of the intermediate principal stress $\sigma_{2}$ and the maximum principal stress $\sigma_{3}$. As the intermediate principal stress $\sigma_{2}$ increases, the triaxial compressive strength $\sigma_{3}$ continues to increase, and $\sigma_{1} / \sigma_{3}$ decreases as the minimum principal stress $\sigma_{1}$ remains unchanged. In this case, under different erosion times, $\sigma_{2} / \sigma_{3}$ also increases, showing an obvious oblique shear failure trend. The angle between the failure surface and the free surface of the specimen is about $20-25^{\circ}$. The failure surface and the direction of the maximum principal stress are mostly $15-30^{\circ}$ inclined cracks, with pyramidal broken blocks. With the increase of the stress ratio, $\sigma_{1} / \sigma_{3}$ decreases while $\sigma_{2} / \sigma_{3}$ increases, and as a result, cracks continue to grow and pyramids become increasingly inclined.

\section{Analysis and Discussion}

As a typical multiphase composite material, concrete features complex internal structure and prominent heterogeneity. In the process of internal cement setting and hardening, there will inevitably be initial defects (micro cracks, pores, etc.) between coarse and fine aggregates and the cement paste formed by cement mortar, which will play an important role in the mechanical properties of concrete.

Rankine criterion [31-33] in classical strength theory holds that when brittle failure occurs in concrete, the stress at the failure point reaches the uniaxial tensile strength $f_{t}$ of concrete. The expression of Rankine criterion in principal stress space is as follows:

$$
\begin{aligned}
& \sigma_{3}=f_{t}, \\
& \sigma_{2}=f_{t}, \\
& \sigma_{1}=f_{t} .
\end{aligned}
$$

The stress invariants of Rankine criterion are expressed as follows:

$$
f\left(I_{1}, J_{2}, \theta\right)=2 \sqrt{3 J_{2}} \cos \theta+I_{1}-3 f_{t}=0,
$$



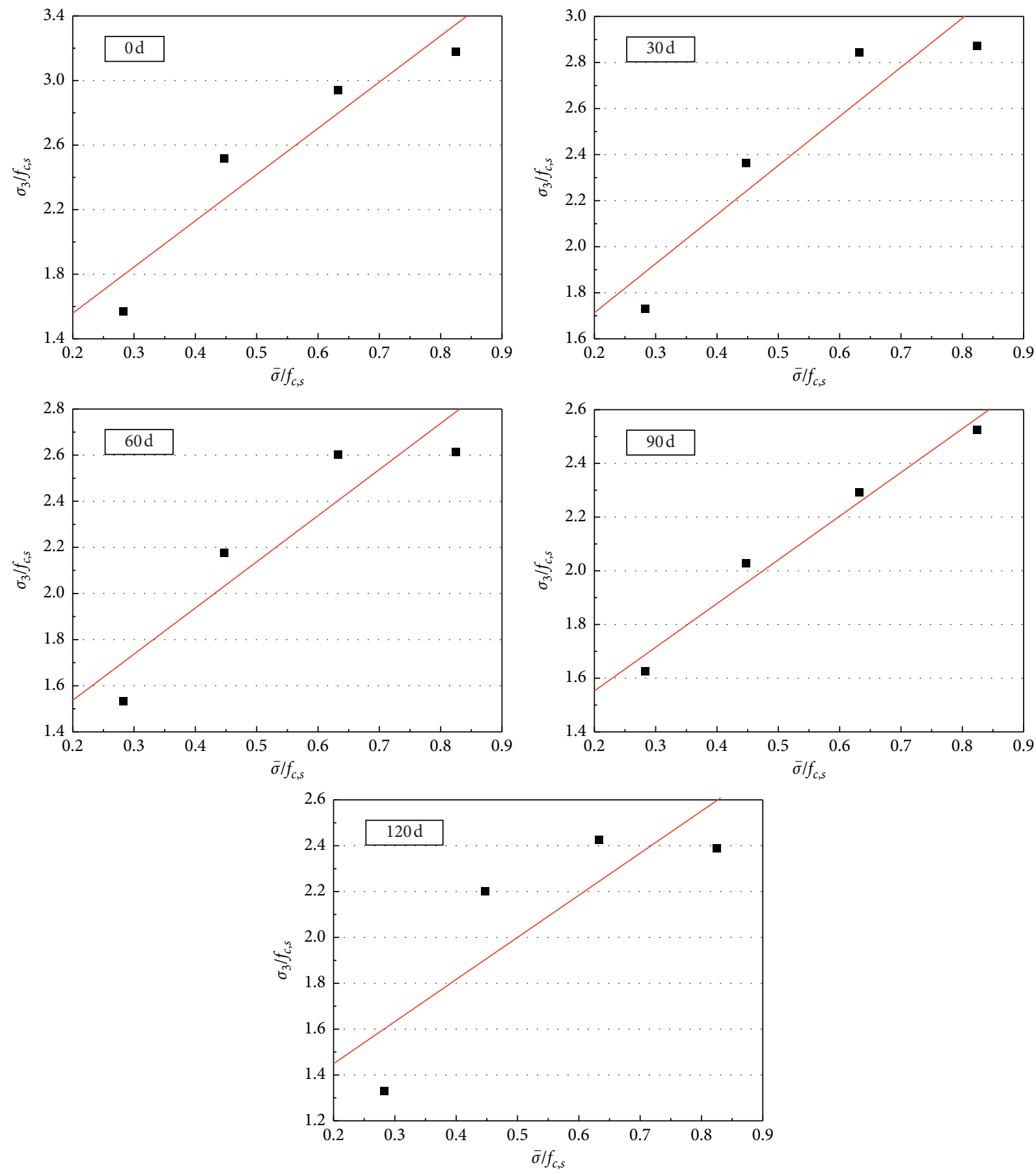

FIGURE 13: Fitting curve of triaxial static compressive strength of concrete.

, where $I_{1}$-the first invariant of stress tensor; $J_{2}$-the second invariant of stress partial tensor.

Tresca criterion [31-33], judging by the maximum shear stress, holds that when the stress at any point in the concrete material reaches the maximum shear stress $k$ of the material, the material will be damaged and plastic yield will occur. The expression of Tresca criterion in principal stress space is as follows:

$$
\max \left(\frac{1}{2}\left|\sigma_{1}-\sigma_{2}\right|, \frac{1}{2}\left|\sigma_{2}-\sigma_{3}\right|, \frac{1}{2}\left|\sigma_{3}-\sigma_{1}\right|\right)=k .
$$

The stress invariants of Tresca criterion are expressed as follows:

$$
f\left(J_{2}, \theta\right)=\sqrt{J_{2}} \sin \left(\theta+\frac{\pi}{3}\right)-k=0 .
$$

In addition, the Griffith theory, which considers both compressive strength and tensile strength of materials, holds that the failure of concrete materials originates from the initiation and propagation of micro cracks and pores $[32,36]$. The nonhomogeneous region inside the material, 

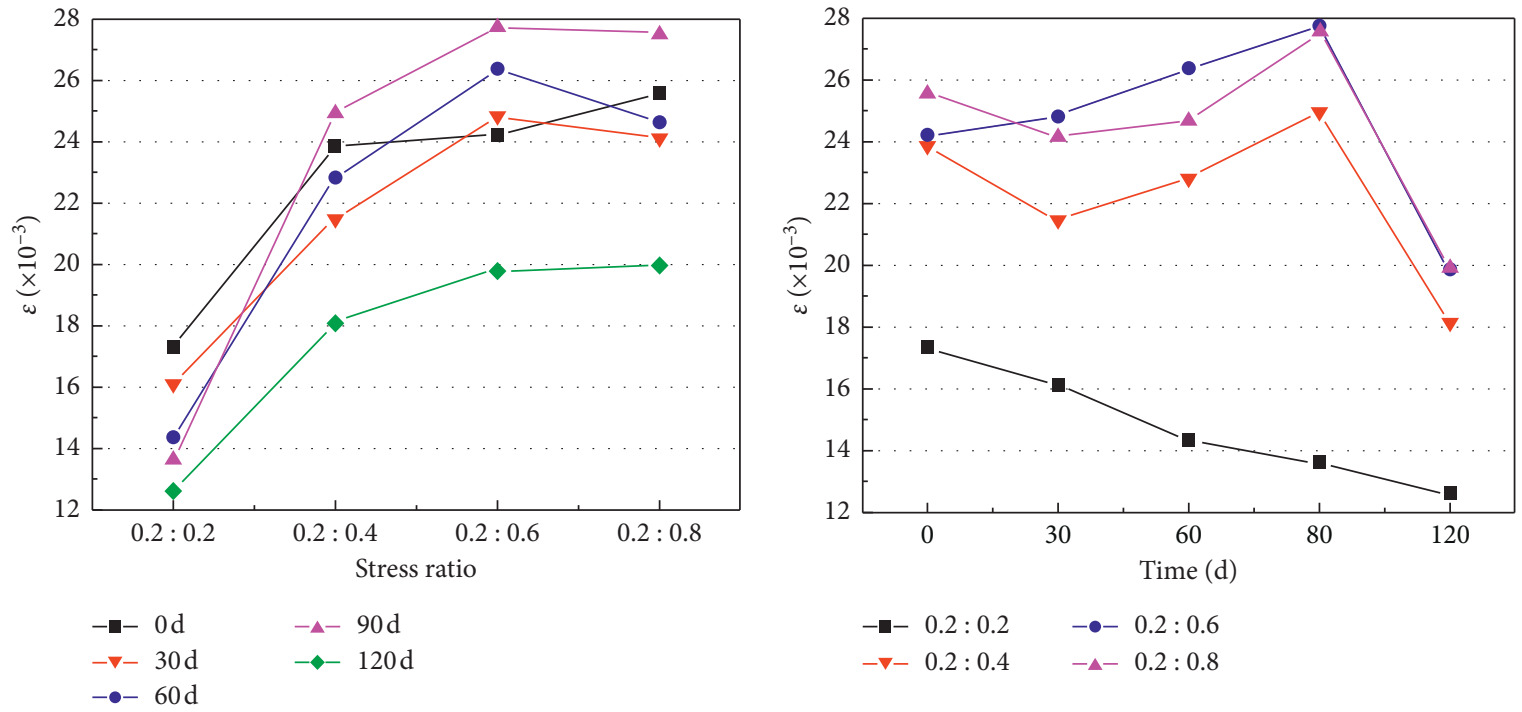

FIGURE 14: Variation of peak strain of concrete specimens.
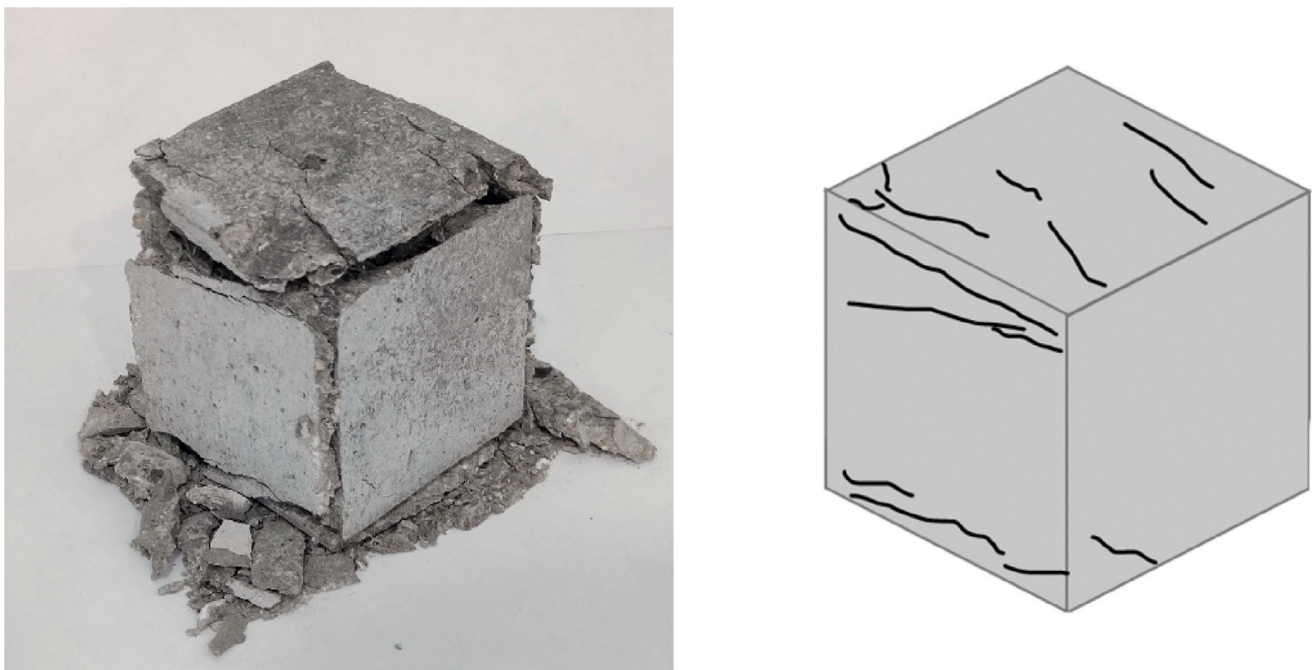

Figure 15: Typical failure modes and crack characteristics of concrete under triaxial static compression.

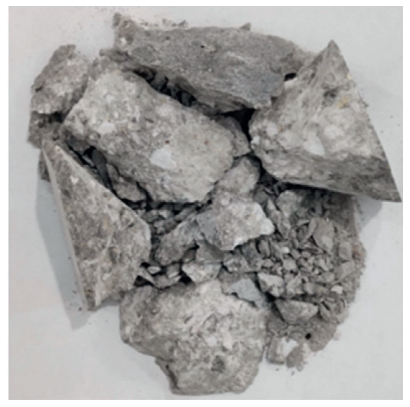

$0.2: 0.2$

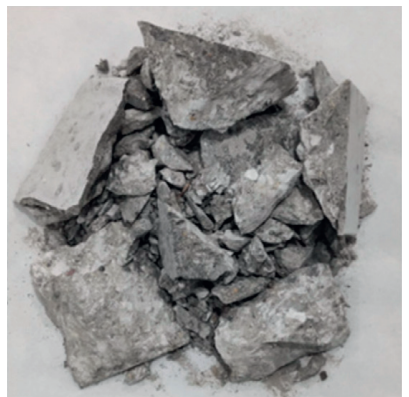

$0.2: 0.4$

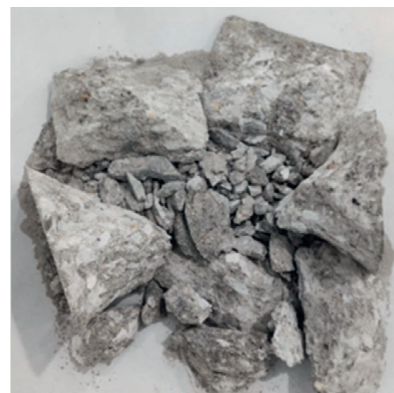

$0.2: 0.6$

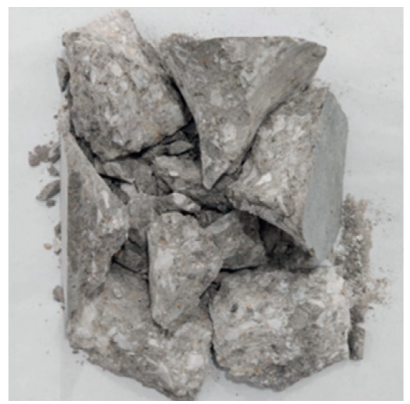

$0.2: 0.8$

FiguRE 16: Fracture morphology of specimens under different stress ratios.

especially the edges of cracks and pores, is prone to stress concentration under the action of external load, and the material failure occurs gradually with the propagation of cracks. Assuming that there are a series of cracks in the specimen, and the direction of the long axis of the crack is at an angle $\alpha$ with the first principal stress $\sigma_{3}$ of the specimen, then according to the Griffith theory, when the compressive stress is appropriate in size and direction, the edges and ends 
of the axial or off-axis crack will produce a high tensile stress. When the tensile stress exceeds the tensile strength of the material, it will cause cracks at the edges and ends. However, when the specimen is under multidirectional complex stress state, the first principal stress will promote crack growth, the second principal stress and the third principal stress perpendicular to the direction of the first principal stress will force the axial cracks to close, thus further enhancing the internal compactness of the specimen, improving the initial defects in the concrete, and enhancing the stress threshold required for crack propagation. At the same time, according to the Poisson effect, cracking and deformation of the specimen will be restrained.

The mechanical properties of concrete specimens under triaxial static compression after sulfate attack are the result of the superposition and mutual coupling of the reinforcement effect induced by the confining pressure and the deterioration effect induced by sulfate attack. The triaxial static compression test results are significantly different from those of uniaxial static compression test, and the essential difference between these two tests lies in the multiaxial stress, that is, the confining pressure effect. Many studies have shown that the compressive strength of concrete materials is obviously enhanced under multiaxial compression, showing a significant confining pressure effect. From the results of the triaxial static compression test, the strength of the specimen differs greatly under different combinations of stress ratio. Before reaching the confining pressure level that induces internal defect development and fracture cracking of the specimen, the strength of the specimen tends to increase with the increase of the confining pressure. This is because the confining pressure can improve the original defects in the material by compressing and closing initial cracks. Moreover, the second principal stress and third principal stress also play a role in laterally restraining and limiting deformation and cracking when applying load on the principal axis until the specimen fails. With the increase of the sulfate attack time and the deepening of the erosion degree, the inside of the specimen first becomes dense, then cracks heavily and loosens. The experimental results show that the denser the specimen (the 30-90 days groups) is, the weaker the reinforcement effect of the confining pressure is. However, the triaxial static compressive strength is still high because of the high basic static compressive strength. As the degree of erosion deepens, on the 120th day, although specimens with loose structure induces high reinforcement effect of confining pressure, the triaxial compressive strength of the specimen even declines at a high confining pressure level. This is because the strength of the specimen has declined due to the severe deterioration effect induced by sulfate attack, and before the load is applied on the principal axis, the specimen suffered crushing failure at a high confining pressure level.

In the triaxial static compression test, restricted by the confining pressure, the ductility of the specimen is notably enhanced and the failure characteristics change from brittle failure under uniaxial compression to ductile failure under triaxial compression. Under the same attack time, the peak strain shows an upward trend on the whole as the confining pressure increases. The increase rate is high at first, then slows down, and at last remains roughly the same or slightly decreases under the high confining pressure. As erosion deepens, the variation of peak strain does not show regular change at the same stress ratio. The peak strain changes slightly at the early and middle stages of erosion but shows a sharp decline when the specimen is severely deteriorated on the 120th day.

\section{Conclusions}

Here, integrated true triaxial static and dynamic loading test system was used to carry out uniaxial and triaxial static compression tests on concrete specimens immersed in 15\% sulfate solution for up to 120 days. The variation of concrete strength, deformation, and other mechanical properties were investigated and the influence mechanism of sulfate attack and true triaxial static compression load on the mechanical properties of concrete was discussed. The main conclusions are as follows:

(1) The uniaxial compressive strength of concrete after sulfate attack increases first, and then decreases with the increase of attack time, and reaches the peak on the 30th day, with an increase rate of $16.57 \%$.

(2) The confining pressure enhancement effect is obvious under triaxial compression, and the compressive strength of concrete after sulfate attack increases significantly. Under the combination of 0-day attack and $0.2: 0.8$ stress ratio, the triaxial compressive strength of concrete increases the most, which is 3.18 times of uniaxial compressive strength.

(3) The sulfate attack deterioration is significant at a high confining pressure, and the sensitivity of triaxial compressive strength of concrete to lateral compressive stress level is declined as the erosion deepens.

(4) Under the triaxial compression state, the confining pressure can restrain the deformation cracking of concrete, leading to enhanced ductility, and the failure pattern of specimens is between splitting failure and oblique shear failure.

This study only covers the static load with low strain rate and four kinds of static triaxial stress ratios. Further studies on mechanical properties of concrete after sulfate attack across a wider strain rate and a three-dimensional stress ratio range are necessary. In addition, XRD tests and SEM tests should be considered in further investigation of the change mechanisms of concrete microstructure.

\section{Data Availability}

The data used to support the findings of this study are available from the corresponding author upon reasonable request.

\section{Conflicts of Interest}

The authors declare that there are no conflicts of interest. 


\section{Authors' Contributions}

Wei Xia was in charge of conceptualization, methodology, data curation, formal analysis, and the writing of the original draft. Erlei Bai was involved in project administration and validation. Jinyu $\mathrm{Xu}$ was responsible for visualization and investigation. Gaojie Liu was concerned with writing, reviewing, editing, and visualization.

\section{Acknowledgments}

The authors thank the National Natural Science Foundation of China (Grant no. 51208507) for the financial support.

\section{References}

[1] C. Smerzini, J. Avilés, R. Paolucci, and F. J. Sánchez-Sesma, "Effect of underground cavities on surface earthquake ground motion under SH wave propagation," Earthquake Engineering \& Structural Dynamics, vol. 38, no. 12, pp. 1441-1460, 2009.

[2] J.-W. Zhao, F.-L. Peng, T.-Q. Wang, X.-Y. Zhang, and B.-N. Jiang, "Advances in master planning of urban underground space (UUS) in China," Tunnelling and Underground Space Technology, vol. 55, pp. 290-307, 2016.

[3] Z.-j. Ren, X.-h. Peng, N. Hu, and C.-h. Yang, "A micromechanical damage model for rocks and concretes under triaxial compression," Applied Mathematics and Mechanics, vol. 30, no. 3, p. 323, 2009.

[4] P. Folino and X. Hernán, Insights into the Triaxial Behaviour of Recycled Aggregate Concrete, Springer International Publishing, Berlin, Germany, 2017.

[5] S. Xu, J. Shan, L. Zhang et al., "Dynamic compression behaviors of concrete under true triaxial confinement: an experimental technique," Mechanics of Materials, vol. 140, Article ID 103220, 2020.

[6] Z. Guo and C. Wang, "Investigation of strength and failure criterion of concrete under multi-axial stresses," China Civil Engineering Journal, vol. 24, no. 3, pp. 1-14, 1991.

[7] Z. P. Bazant, Finite Analysis of Reinforced Concrete, Hohai University Press, Nanjing, China, 1988.

[8] T. Hampel, K. Speck, S. Scheerer, R. Ritter, and M. Curbach, "High-performance concrete under biaxial and triaxial loads," Journal of Engineering Mechanics, vol. 135, no. 11, pp. 12741280, 2009.

[9] Y. Malecot, L. Zingg, M. Briffaut, and J. Baroth, "Influence of free water on concrete triaxial behavior: the effect of porosity," Cement and Concrete Research, vol. 120, pp. 207-216, 2019.

[10] D. Chen, X. Yu, R. Liu, S. Li, and Y. Zhang, "Triaxial mechanical behavior of early age concrete: experimental and modelling research," Cement and Concrete Research, vol. 115, pp. 433-444, 2019.

[11] L. Wei, J. Xiao-Guang, and Z. Zhong-Ya, "Triaxial test on concrete material containing accelerators under physical sulphate attack," Construction and Building Materials, vol. 206, pp. 641-654, 2019.

[12] Y. P. Pisheh and S. M. M. M. Hosseini, "Stress-strain behavior of plastic concrete using monotonic triaxial compression tests," Journal of Central South University, vol. 19, no. 4, pp. 1125-1131, 2012.

[13] B. Williams, W. Heard, S. Graham, and X. Nie, "Effect of specimen geometry on triaxial compressive response of highstrength concrete," Construction and Building Materials, vol. 244, Article ID 118348, 2020.
[14] M. Mohammadi and Y.-F. Wu, "Triaxial test for concrete under non-uniform passive confinement," Construction and Building Materials, vol. 138, pp. 455-468, 2017.

[15] Z. Zhongya, J. Xiaoguang, and L. Wei, "Long-term behaviors of concrete under low-concentration sulfate attack subjected to natural variation of environmental climate conditions," Cement and Concrete Research, vol. 116, pp. 217-230, 2019.

[16] E. I. Nadelman and K. E. Kurtis, "Durability of Portlandlimestone cement-based materials to physical salt attack," Cement and Concrete Research, vol. 125, Article ID 105859, 2019.

[17] N. Ghafoori, H. Diawara, and S. Beasley, "Resistance to external sodium sulfate attack for early-opening-to-traffic Portland cement concrete," Cement and Concrete Composites, vol. 30, no. 5, pp. 444-454, 2008.

[18] J.-k. Chen and M.-q. Jiang, "Long-term evolution of delayed ettringite and gypsum in Portland cement mortars under sulfate erosion," Construction and Building Materials, vol. 23, no. 2, pp. 812-816, 2009.

[19] H. Song, J. Chen, and J. Jiang, "An internal expansive stress model of concrete under sulfate attack," Acta Mechanica Solida Sinica, vol. 29, no. 6, pp. 610-619, 2016.

[20] N. Cefis and C. Comi, "Chemo-mechanical modelling of the external sulfate attack in concrete," Cement and Concrete Research, vol. 93, pp. 57-70, 2017.

[21] A. Choudhary, M. Malik, S. Tiwari, A. dubey, U. Sharma, and A. Kumar, "Concrete deterioration due to sulphate-a case study," Materials Today: Proceedings, vol. 5, no. 9, pp. 17952-17957, 2018.

[22] G. Zhao, J. Li, M. Shi et al., "Degradation mechanisms of castin-situ concrete subjected to internal-external combined sulfate attack," Construction and Building Materials, vol. 248, Article ID 118683, 2020.

[23] A. Bonakdar and B. Mobasher, "Multi-parameter study of external sulfate attack in blended cement materials," Construction and Building Materials, vol. 24, no. 1, pp. 61-70, 2010.

[24] I. Tai, S.-H.-P. Cavalaro, I. Segura et al., "Simplified methodology to evaluate the external sulfate attack in concrete structures," Materials and Design, vol. 89, pp. 1147-1160, 2016.

[25] A. R. Suleiman, A. M. Soliman, and M. L. Nehdi, "Effect of surface treatment on durability of concrete exposed to physical sulfate attack," Construction and Building Materials, vol. 73, no. 30, pp. 674-681, 2014.

[26] H. Siad, L. Mohamed, Ş. Mustafa et al., "Preconditioning method for accelerated testing of concrete under sulfate attack," ACI Materials Journal, vol. 113, no. 4, 2016.

[27] M. H. Alyami, R. S. Alrashidi, H. Mosavi et al., "Potential accelerated test methods for physical sulfate attack on concrete," Construction and Building Materials, vol. 229, Article ID 116920, 2019.

[28] W. Ren and J. Xu, "Fractal characteristics of concrete fragmentation under impact loading," Journal of Materials in Civil Engineering, vol. 29, no. 4, Article ID 04016244, 2016.

[29] X. Sun, K. Zhao, Y. Li et al., "A study of strain-rate effect and fiber reinforcement effect on dynamic behavior of steel fiberreinforced concrete," Construction and Building Materials, vol. 158, pp. 657-669, 2018.

[30] L. Jiang and D. Niu, "Study of constitutive relation of concrete under sulfate attack and drying-wetting cycles," Journal of China University of Mining and Technology, vol. 46, no. 1, pp. 66-73, 2017. 
[31] J. Li, Triaxial Experimental Research and Numerical Simulation of Concrete under Mixed Load Path, Beijing Jiaotong University, Beijing, China, 2017, in Chinese.

[32] M. Yu and Y. Peng, "Advances in strength theories for materials under complex stress state in the 20th century," Advances in Mechanics, vol. 34, no. 4, pp. 529-560, 2004, in Chinese.

[33] J. Yao, Y. Song, and Z. Zhang, "Experimental study on strength and deformation characteristic of normal concrete under triaxial compression," Building Science, vol. 27, no. 7, pp. 28-31, 2011, in Chinese.

[34] D. Chen, X. Yu, M. Guo, Y. Liao, and F. Ouyang, "Study on the mechanical properties of the mortars exposed to the sulfate attack of different concentrations under the triaxial compression with constant confining pressure," Construction and Building Materials, vol. 146, pp. 445-454, 2017.

[35] T. Ikumi, I. Segura, and S. H. P. Cavalaro, "Effects of biaxial confinement in mortars exposed to external sulfate attack," Cement and Concrete Composites, vol. 95, pp. 111-127, 2019.

[36] C. A. Ross, J. W. Tedesco, and S. T. Kuennen, "Effects of strain-rate on concrete strength," ACI Material Journal, vol. 92, no. 1, pp. 37-47, 1995. 